\title{
Effects of two oral iron preparations on results of the benzidine test for occult blood in stools
}

\author{
J. D. CUMMING AND H. G. PERCIVAL \\ From the University Health Centre, University of Reading, Berkshire
}

SYNOPSIS Thirty healthy male volunteers were used in this double blind trial. Two kinds of iron preparation and a placebo tablet containing no iron salt were used. The subjects were given one three times a day after meals in courses of 21 tablets. Stools collected before and after administration of the tablets were subjected to a benzidine test (Thornton and Illingworth, 1955). The results showed that both iron preparations increased the number of positive results obtained by means of the benzidine test. The analyses failed to show any significant difference between the effects of the two preparations.

PROCEDURE

Thirty healthy male undergraduates and graduates in strict athletic training and aged from 18 to 36 years volunteered for this study. No rigid dietary restrictions were imposed, but the subjects were asked to avoid 'rare' meats and liver for three days before an experiment and during it. An experiment lasted for eight days. All subjects were required to provide a specimen of their stool in a waxed Mono container on day 1 and were instructed to take one tablet three times a day after meals, and after completing the course to provide a second stool specimen on day 8 . The subjects were arbitrarily divided into three equal groups (A, B, and C) for the series of experiments. All tablets and their containers appeared identical, except that the instruction labels on containers were red, blue, or green. These coloured labels were used so that the tablets given could be identified after the experiments were completed. Red-labelled containers held ferrous sulphate (192 mg.) tablets, blue-labelled containers ferrous fumarate (200 mg.) tablets, and green-labelled containers were filled with placebo tablets. Table I shows the order in which the tablets were taken by members of the three groups.

\section{TABLE I}

ORDER IN WHICH THE COLOUR-CODED TABLETS WERE TAKEN BY THE GROUPS IN THE THREE EXPERIMENTS

\begin{tabular}{|c|c|c|c|}
\hline \multirow[t]{2}{*}{ Group } & \multicolumn{3}{|c|}{ Experiment No. } \\
\hline & 1 & 2 & 3 \\
\hline $\begin{array}{l}\mathbf{A} \\
\mathbf{B} \\
\mathbf{C}\end{array}$ & $\begin{array}{l}\text { Red label } \\
\text { Green label } \\
\text { Blue label }\end{array}$ & $\begin{array}{l}\text { Blue label } \\
\text { Red label } \\
\text { Green label }\end{array}$ & $\begin{array}{l}\text { Green label } \\
\text { Blue label } \\
\text { Red label }\end{array}$ \\
\hline
\end{tabular}

The stools were examined for occult blood using the benzidine test (Thornton and Illingworth, 1955). Since the tests were conducted serially, freshly prepared reagents were dispensed from suitably mounted burettes. The boiling tubes and glass rods used were first thoroughly washed with hot water and liquid soap and rinsed with warm tap water. They were then rinsed three times with demineralized water and dried in an oven. The clean dry tubes and glass rods were next tested with a little benzidine-peroxide mixture (see below). If after 5 sec. no colour change was observed each tube was rinsed twice with demineralized water and labelled. A pea-sized piece of stool obtained from the depths of the specimen was ground in a tube with $5 \mathrm{ml}$. of demineralized water, using a glass rod. The resulting faecal suspension was boiled for exactly two minutes and allowed to cool. Stool specimens which were not homogeneous were 'creamed' before sampling, as recommended by Thornton and Illingworth (1955). Next a series of tubes was prepared, each tube containing $2 \mathrm{ml}$. of a saturated solution of benzidine in glacial acetic acid mixed with $1.25 \mathrm{ml} .10 \mathrm{vol}$. hydrogen peroxide. Approximately $1 \mathrm{ml}$. of the supernatant from a labelled tube of faecal suspension was gently run in on top of the benzidineperoxide mixture contained in an identically labelled tube.

Each tube was examined after one minute and again after 10 minutes, and the result of the test was recorded.

\section{RESULTS}

The results of the benzidine tests performed are summarized in Table II.

Tables III and IV show a significant difference caused by the administration of ferrous sulphate and 
TABLE II

RESULTS OF ALL BENZIDINE TESTS

\begin{tabular}{|c|c|c|c|c|c|c|}
\hline \multirow{2}{*}{$\begin{array}{l}\text { Member No. } \\
\text { in Group }\end{array}$} & \multicolumn{2}{|c|}{ Red Label } & \multicolumn{2}{|c|}{ Green Label } & \multicolumn{2}{|c|}{ Blue Label } \\
\hline & Day 1 & Day 8 & Day 1 & Day 8 & Day 1 & Day 8 \\
\hline
\end{tabular}

Experiment 1

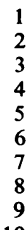

1
2
4
5
6
7
8
9

Experiment 2

$\begin{array}{rllllll}\mathbf{1} & + & - & - & + & - & + \\ \mathbf{2} & + & - & - & - & - & - \\ \mathbf{3} & + & + & - & - & + & + \\ \mathbf{4} & - & + & - & - & - & - \\ \mathbf{5} & - & + & - & - & - & + \\ \mathbf{6} & - & + & - & - & - & - \\ \mathbf{7} & - & + & - & - & - & - \\ \mathbf{8} & - & - & - & - & - & - \\ \mathbf{9} & - & + & - & - & + & + \\ \mathbf{1 0} & - & + & - & - & - & +\end{array}$

Experiment 3

$\begin{array}{rllllll}\mathbf{1} & - & + & - & - & - & + \\ \mathbf{2} & - & - & - & - & - & - \\ \mathbf{3} & - & + & - & - & - & + \\ \mathbf{4} & - & - & + & - & - & - \\ \mathbf{5} & - & + & - & - & - & + \\ \mathbf{6} & - & + & - & - & + & - \\ \mathbf{7} & - & - & - & - & - & - \\ \mathbf{8} & - & - & - & - & - & - \\ \mathbf{9} & - & - & + & - & + & - \\ \mathbf{1 0} & - & + & - & - & - & -\end{array}$

TABLE III

SIGNIFICANT DIFFERENCE CAUSED BY TREATMENT WITH TABLETS FROM RED-LABELLED CONTAINERS ${ }^{1}$

\begin{tabular}{lccc} 
& Before Tablets & After Tablets & Total \\
\hline Positive & 3 & 17 & 20 \\
Negative & 27 & 13 & 40 \\
Total & 30 & 30 & 60
\end{tabular}

${ }^{1} \chi^{2}=15.8$ with 1 degree of freedom $p<\cdot 001$

TABLE IV

SIGNIFICANT DIFFERENCE CAUSED BY TREATMENT WITH TABLETS FROM BLUE-LABELLED CONTAINERS ${ }^{1}$

\begin{tabular}{llll} 
& Before Tablets & After Tablets & Total \\
\hline Positive & 6 & 14 & 20 \\
Negative & 24 & 16 & 40 \\
Total & 30 & 30 & 60
\end{tabular}

${ }^{1} \chi^{2}=4.9$ with 1 degree of freedom $\cdot 02<p<\cdot 05$.
TABLE V

COMPARISON OF TREATMENTS WITH TABLETS FROM RED LABELLED AND BLUE-LABELLED CONTAINERS ${ }^{1}$

\begin{tabular}{lllll} 
& After Red & After Blue & Total & 을 \\
\hline Positive & 17 & 14 & 31 & 을 \\
Negative & 13 & 16 & 29 & $\bar{D}$ \\
Total & 30 & 30 & 60 & $\square$
\end{tabular}

${ }^{1}$ There is no significant difference between the effects of the two treatments.

ferrous fumarate tablets, and Table $\mathrm{V}$ no significant difference between the effects on the stools of theo two kinds of iron tablet.

\section{DISCUSSION}

A major difficulty with this method of testing was in the examination of the tubes after one and 10 minutes. When a well circumscribed blue ring wast present it was often difficult to distinguish it from the dark lower phase of the system, even if the tube was examined against a background of frosted glasse and in a good light.

Another disadvantage of this method was that nor uniformity of colour or of optical density of thes faecal supernatant could be obtained because of the wide normal variation in the colour and consistencyo of stool specimens collected. It was not possibie to⿱ distinguish satisfactorily the weak positive reaction manifested by the appearance of a greenish ring (Thornton and Illingworth, 1955). This was therefore not used as a criterion for a positive reaction to this test.

In our work two criteria were adopted to deter mine consistently whether the test was giving a posio tive or a negative result. The benzidine test was reap. as positive after one or 10 minutes if a blue ring appeared at the interface or if a definite blue coloue of the two-phase system could be seen. It was also read as positive after 10 minutes if within $5 \mathrm{sec}$. of gently mixing the phases a definite blue colour of the whole mixture was seen.

Using these criteria it was noted that of the $12 \mathbb{F}^{\circ}$ control specimens of stool tested, i.e. all day $N$ specimens and day 8 placebo specimens, 12 gavङ positive results. These were regarded as false posio tives because all the subjects were healthy, had re mained free from all bowel disturbances, and were in strict training for rugby football.

It appears from our results that both ferrouso sulphate $(192 \mathrm{mg}$.) and ferrous fumarate $(200 \mathrm{mg}$. $\Phi$ tablets significantly increased the number of positive occult blood results recorded using the benzidine test There was no significant difference between the effects of the two iron salts as determined by this 
test. The placebo tablets had no demonstrable effect on the stools. These results differ from those of earlier studies of the effects of iron preparations on the stools, as shown by the benzidine test (Illingworth 1965; Thornton and Illingworth, 1955; Peranio and Bruger, 1951). They agree with the conclusions of Kohn and O'Kelly (1955).

This work was done during the tenure of a Medical Research Council junior research fellowship by H.G.P.
The authors acknowledge with gratitude the help received from Glaxo Pharmaceuticals, who supplied the tablets and supported the cost of the experiment.

\section{REFERENCES}

Illingworth, D. G. (1965). J. clin. Path., 18, 103.

Kohn, J., and O'Kelly, T. J. (1954). Ibid., 8, 249.

Peranio, A., and Bruger, M. (1951). J. Lab. clin. Med 38, 433.

Thornton, G. H. M., and Illingworth, D. G.(1955). Gastroenterology, 28, 593 . 